4 Prause G. 15 Jahre präoperative Ambulanz in Graz. Anaesthesist 1994; 43: 223-8.

5 Janesko $M$, Unk E, Palos $L$. Unsere Erfahrungen mit der Anasthesieambulanz. Anaesthesist 1983; 32: 174-6.

6 Finegan BA. Preadmission and outpatient consultation clinics (Editorial). Can J Anaesth 1992; 39: 1009-11.

7 Conway JB, Goldberg J, Chung F. Preadmission anaesthesia consultation clinic. Can J Anaesth 1992; 39: 1051-7.

\section{Maternal death following epidural anaesthesia}

\section{To the Editor:}

We read with interest the recent case report by Morgan ${ }^{1}$ describing a maternal death following epidural anaesthesia for Caesarean section in a patient with unsuspected sepsis.

The diagnosis of Group A streptococcus sepsis may be the most likely diagnosis, however we feel that a differential diagnosis should have been considered in their discussion. A cardiorespiratory arrest occurring eight minutes after injection of local anaesthetic into the epidural space should alert any anaesthetist of a complication arising directly from the epidural. An accidental intrathecal injection of local anaesthetic cannot be totally excluded particularly when $12 \mathrm{ml}$ of the local anaesthetic were injected through the Tuohy needle. A correctly positioned catheter in the epidural space at post mortum does not exclude intrathecal injection in this patient.

This article also states that the use of epidural anaesthesia can be considered in the resuscitated septic patient, but it fails to stress the risk of epidural abscess or meningitis in a patient with systemic infection.

T.M. Bourne FRCA

M.C. Mushambi FRCA

Leicester Royal Infirmary

Leicester LE1 5WW

England

\section{REFERENCE}

1 Morgan PJ. Maternal death following epidural anaesthesia for Caesarean section delivery in a patient with unsuspected sepsis. Can J Anaesth 1995; 42: 330-4.

\section{REPLY}

I appreciate the interest of Drs. Boume and Mushambi in my recent article.

This patient came to the operating room with an indwelling intravenous catheter and had received approximately 1 litre of a balanced salt solution. Her blood pressure was 135/84 $\mathrm{mmHg}$. She was receiving oxygen by face mask. In the right lateral position, after sterile preparation of the area, an epidural was performed without difficulty at the $L_{3-4}$ interspace. Several gentle aspiration attempts through the epidural needle, after intermittent incremental injections of local anaesthetic, failed to reveal any cerebrospinal fluid or blood. This took place over approximately 3 minutes. At this time, an epidural catheter was inserted. Aspiration of the catheter did not yield any CSF or blood and $3 \mathrm{ml}$ of the same anaesthetic solution (carbonated lidocaine $2 \%$ with 1:200,000 epine- phrine and $2 \%$ mepivacaine in 1:1 ratio) was given. Upon questioning, the patient had no symptoms of sensory analgesia and a further $3 \mathrm{ml}$ of the solution was injected. The epidural catheter was then taped to the patient's back. Approximately 5-6 min had elapsed since the initial injection. The patient then moved herself onto her back. She was able to lift her hips, straighten her legs and again had no symptoms of the onset of sensory analgesia. AT the first sign of respiratory difficulty, the trachea was intubated and her lungs were ventilated with $100 \%$ oxygen and cardiopulmonary resuscitation begun.

After the unsuccessful resuscitative effort, the anaesthetist's provisional diagnosis was that of an unintentional total spinal anaesthetic. The differential included intravascular injection of local anaesthetic, amniotic fluid embolus, pulmonary embolus or myocardial infarction. The possibility of sepsis was not even considered at this time. The anaesthetist decided to speak with the coroner and suggest that it was imperative to know whether an unintentional total spinal had occurred. The coroner therefore decided to bring in a neuropathologist to address this issue. After meticulous attention to the subarachnoid, dura and epidural areas, the neuropathologist's findings were that there was no abnormality, the dura was intact and the epidural catheter was located in the epidural space.

The key question is why, despite immediate resuscitation, did our patient have a fatal outcome. The trachea was immediately intubated and the lungs ventilated with $100 \%$ oxygen. Repeated auscultation by several physicians noted the air entry to be equal and bilateral. The tracheal tube, placed at the beginning of the resuscitative efforts was left exactly as it was, and was found by the coroner to be in the trachea. At autopsy, serum lidocaine concentrations were normal. It is known that aortocaval compression in the parturient can compromise cardiopulmonary resuscitative efforts.' The American Heart Association has advocated early delivery of the mother to optimize the resuscitative efforts. ${ }^{2}$ The evacuation of the uterus will relieve aortocaval compression and improve venous return. If possible, the baby should be delivered within five minutes to assure the best possible outcome and there are reports of infant survival after maternal arrest of more than 20 minutes. ${ }^{3}$

In our case, the babies were delivered within four minutes of the maternal arrest. The maternal cardiopulmonary resuscitative efforts continued for 31 min after the uterus had been evacuated. The patient did not respond to epinephrine or any other measures as outlined in the report. At autopsy, blood and tissue cultures of multiple organs grew Group A streptococcus. There were massive areas of necrosis of multiple organ systems including the myocardium, lung, liver and kidney.

Three reviews of more than 500,000 obstetric patients who received epidural anaesthesia reported two cases of epidural infection and no cases of meningitis. Treatment with an antibiotic therapy may decrease the chance of the development of meningitis or epidural abscess. ${ }^{4}$ To deny the beneficial effects of epidural anaesthesia because of an unknown risk of CNS infection, is at best, questionable. It is my practice to assess the septic patient's history, physical and laboratory findings. If the patient is euvolaemic, antibiotic therapy has been given and the risk-benefit ratio favours the administration of epidural anaesthesia, I will do so in a carefully titrated fashion. Other obstetrical anaesthetists follow the same guidelines. ${ }^{4}$

\section{P.J. Morgan MD FRCPC}

Toronto 


\section{REFERENCES}

1 Thornhill ML, Camann WR. Cardiovascular disease. In: Chestnut DH (Ed.). Obstetric Anesthesia. St. Louis: Mosby, 1994: 746-79.

2 American Heart Association. Guidelines for cardiopulmonary resuscitation and emergency cardiac care. Special resuscitation situations. JAMA 1992; 268: 2242-50.

3 Lopez-Zeno JA, Carlo WA, O'Grady IP, Fanaroff AA. Infant survival following delayed postmortem cesarean delivery. Obstet Gynecol 1990; 76: 991-2.

4 Carp $H C$, Chestnut $D H$. Fever and infection. In: Chestnut DH (Ed.). Obstetric Anesthesia. St. Louis: Mosby, 1994: 686-98.

\section{Calculation of dead space volume}

To the Editor:

We read with interest the article by Mora et al.' regarding sedative and ventilatory effects of midazolam. They used the following equation for the calculation of dead space volume:

$\mathrm{Vd}=\left(\mathrm{EPaCO}_{2}-\mathrm{PETCO}\right)_{2} \times(\mathrm{Vt}-$ Valve dead space $) / \mathrm{EPaCO}_{2}$

The use of end-tidal partial pressure of $\mathrm{CO}_{2}\left(\mathrm{PETCO}_{2}\right)$ is questionable. It seems to us that the mixed expired, rather than endtidal $\mathrm{PCO}_{2}$, should be used.

The volume of $\mathrm{CO}_{2}$ eliminated in the expired gas each minute $\left(\mathrm{CO}_{2}\right.$ production, $\left.\dot{\mathrm{V}} \mathrm{CO}_{2}\right)$ equals the product of minute ventilation $\left(\dot{\mathrm{V}}_{\mathrm{E}}\right)$ and mixed expired $\mathrm{CO}_{2}$ concentration $\left(\mathrm{FE} \mathrm{CO}_{2}\right)$ :

$\dot{\mathrm{V}} \mathrm{CO}_{2}=\left(\mathrm{FECO}_{2}\right) \times(\dot{\mathrm{VE}})$

The volume of $\mathrm{CO}_{2}$ eliminated from the body is also equal to the sum total of $\mathrm{CO}_{2}$ volume in the alveoli and in the dead space:

$\dot{\mathrm{V} C \mathrm{O}_{2}}=\left(\dot{\mathrm{V}}_{\mathrm{A}}\right) \times\left(\mathrm{FACO}_{2}\right)+\left(\dot{\mathrm{V}}_{\mathrm{D}}\right) \times\left(\mathrm{FDCO}_{2}\right)$

where $\mathrm{FACO}_{2}$ is the $\mathrm{CO}_{2}$ concentration in the alveoli, $\mathrm{FDCO}_{2}$ is the $\mathrm{CO}_{2}$ concentration in the dead space (which equals inspired $\mathrm{CO}_{2}$ concentration, $\mathrm{FICO}_{2}$ ), and $\dot{\mathrm{V}}_{\mathrm{A}}$ and $\dot{\mathrm{V}}_{\mathrm{D}}$ are alveolar and dead space ventilation, respectively.

Setting equation 1 against equation 2 , and using the relationship between $\dot{V}_{E}, \dot{V}_{A}$ and $\dot{V}_{D}\left(\dot{V}_{E}=\dot{V}_{A}+\dot{V}_{D}\right)$, and substituting $\mathrm{FICO}_{2}$ for $\mathrm{FDCO}_{2}$, results in the equation

$\left(\mathrm{FECO}_{2}\right) \times(\dot{\mathrm{V}})=$

$$
(\dot{\mathrm{VE}}-\dot{\mathrm{V}} \mathrm{D}) \times\left(\mathrm{FACO}_{2}\right)+(\dot{\mathrm{V} D}) \times\left(\mathrm{FICO}_{2}\right)
$$

Since $\mathrm{FICO}_{2}$ is approximately zero, and since $\mathrm{FACO}_{2}$ approximates arterial $\mathrm{CO}_{2}\left(\mathrm{FaCO}_{2}\right)$, and since ventilation $(\dot{V})$ is the product of volume (V) and respiratory rate, further algebraic manipulation yields the equation:

$\mathrm{VD}=\left(\mathrm{FaCO}_{2}-\mathrm{FECO}_{2} \times(\mathrm{VT}) / \mathrm{FaCO}_{2}\right.$

which is known as the Bohr equation. ${ }^{2}$

\section{Ze'ev Shenkman MD}

Ioan Mircea Crisnic MD

Alexander Avidan MD

Department of Anesthesiology and Critical Care Medicine

Hadassah University Hospital

Hebrew University, Hadassah Medical School

P.O. Box 12000

Jerusalem 91120

Israel

\section{REFERENCES}

1 Mora TC, Torjman $M$, White $P F$. Sedative and ventilatory effects of midazolam infusion: effect of flumazenil reversal. Can J Anaesth 1995; 42: 677-84.

2 Benum of $J L$. Respiratory physiology and respiratory function during anesthesia. I $n$ : Miller RD (Ed.). Anesthesia 3rd ed. New York: Churchill Livingstone Inc., 1990: 505-49.

\section{REPLY}

We appreciate the comments of Drs. Shenkman, Crisnic and Avidan regarding the calculation of physiologic dead space. ${ }^{I}$ We apologize for the typographical error in expressing the Bohr equation. Indeed mixed expired values $\left(P \bar{E} C \mathrm{C}_{2}\right)$ were used for the calculation of physiologic dead space rather than $\mathrm{PETCO}_{2}$ values.

Our instrumentation consisted of a metabolic cart (MGC 2001) which is primarily designed to measure $\mathrm{VE}_{\mathrm{V}} \mathrm{VO}_{2}$ and $\mathrm{VCO}_{2}$ and, therefore, provides an $\mathrm{FECO}_{2}$ measurement from the waveform analyzer trace. $\mathrm{Had}$ we used $\mathrm{PETCO}_{2}$ values for our calculations, we would have obtained measurements well below the normal physiological range since $\mathrm{PaCO}_{2}$ and $\mathrm{PETCO}_{2}$ values are similar in patients with normal lung physiology.

Marc Torjman MD

Thomas Jefferson University

Philadelphia

Christina T. Mora MD

Stanford University

Paul F. White PhD MD FANZCA

University of Texas Southwestern Medical Center

Dallas

\section{REFERENCE}

1 Mora $C T$, Torjman $M$, White $P F$. Sedative and ventilatory effects of midazolam infusion: effect of flumazenil reversal. Can J Anaesth 1995; 42: 677-84.

\section{Erratum}

Orser BA. Medication labels: for whose benefit? (Correspondence). Can J Anaesth 1996; 43: 194.

Please note that in the above Letter to the Editor, Dr. $R$. Chen, the primary author, was inadvertently omitted. It should read:

Chen $R$, Orser $B A$. 